\title{
UNA PERSPECTIVA ANTI-REALISTA SOBRE: LENGUAJE, PENSAMIENTO, LÓGICA E HISTORIA DE LA FILOSOFÍA ANALÍTICA (ENTREVISTA CON MICHAEL DUMMETT ${ }^{1}$ )
}

\author{
Fabrice Pataut \\ Institut d'Histoire et de Philosophie \\ Des Sciences et des Techniques \\ Universite de Paris, France.
}

\section{Frege y Wittgenstein}

Fabrice Pataut: Usted es uno de los filósofos más prominentes de la tradición analítica, y ha dedicado mucho de su tiempo al estudio de Frege, quien comenzó la tradición un poco más de un siglo atrás. Es bastante inusual proceder de este modo entre los filósofos analíticos. No tienden a preocuparse demasiado sobre lo que los autores realmente dicen. Usualmente tratan sobre los tópicos directamente; o al menos muchos se inclinan a hacer esto. Usted afirma en el prefacio de la segunda edición de Frege: Philosophy of Language que una discusión provechosa sobre estas doctrinas debe posponerse, hasta que se haya alcanzado acuerdo sobre el contenido básico de las doctrinas de Frege ${ }^{2}$. Ahora, en un sentido, una gran parte de la filosofía tal como se practica en la tradición analítica, consiste en una discusión sobre estas doctrinas y no parece que se haya alcanzado algún acuerdo sobre lo que podría aceptarse como sus interpretaciones correctas -salvo respecto de algún acuerdo sobre los principios de la exégesis de la filosofía de Frege-.

Permítanme comenzar con una pregunta deliberadamente ingenua: ¿Qué es lo peculiar en el caso de Frege? ¿Quiénes somos nosotros para marcar el hecho de que ningún acuerdo se haya alcanzado con relación al contenido básico de las doctrinas de Frege? Existe un amplio desacuerdo en relación a ellas y más aún, se podría brindar una imagen de la filosofía analítica como un constante

\footnotetext{
${ }^{I}$ La entrevista tuvo lugar en Oxford el 10 de Septiembre de 1992. Mientras trabajaba en la cinta de la entrevista, decidí reunir referencias de libros y artículos en notas a pié de página, de tal modo que el lector pueda seguir fácilmente el curso de la conversación. Luego dividí el texto en secciones, de acuerdo a los tópicos que fueron discutidos. Parte del material de las transcripciones originales ha sido ya editado. Debo agradecer a Michael Dummett por su paciencia, y a ambos, a él y Anne Dummett por su amable hospitalidad. Timothy Tessin colaboró en la preparación de los typescript de la publicación.

${ }^{2}$ Frege:Philosophy of Language, Duckworth, London, 1st ed., 1973; Harvard University Press, Cambridge, Mass., 2nd ed., 1981, p. XV.
} 
retrabajo y discusión de aquello con lo que Frege comenzó, como un intento de resolver sus puzzles.

Michael Dummett: Pienso que es verdad. Su última afirmación conlleva una gran verdad, ya que Frege tuvo éxito en formular preguntas de un modo que todavía podemos responder. Cuando se estudia a los filósofos del pasado, en casi todos los casos, sus problemas se tienen que reformular antes de discutirlos. Con Frege, casi todos los problemas están formulados de un modo tal que nos sentimos afines a ellos. Por supuesto, hay cosas que Frege no vio o de las que no estaba enterado y de las cuales nosotros hemos tomado conocimiento. Pero, en mi opinión, él deja un punto de partida extremadamente bueno, para una gran cantidad de problemas filosóficos.

El fenómeno del que usted habla me sorprendió y me sorprende aún de algún modo. Cuando escribí mi primer libro sobre Frege, no pensé que había demasiado espacio para controversias sobre lo que él quería decir ${ }^{3}$. Pensé que uno tenía que reflexionar mucho sobre eso, no tanto para determinar lo que él quería decir sino, fundamentalmente, para penetrar profundamente en la cuestión y ver todas sus implicancias. Y luego disfruté leyendo un número de cosas libros, artículos, etc.- que proponían interpretaciones radicalmente nuevas de Frege, muchas de las cuales me resultaban aviesas. Y no puedo explicar completamente este fenómeno. La oración que usted registró, supongo que probablemente fue escrita en un estado de irritación. modo leve.

FP: Fue un modo bastante radical de presentarlo, para decirlo de un

MD: Sí, es correcto, y no quiero cambiarlo. Por supuesto, podemos discutir Frege antes de alcanzar un total acuerdo. Pero es justamente muy irritante. $Y$ esto simplemente sucede. Hay un número de libros que se ocupan de decir: "bueno, se ha malentendido siempre a Frege antes que yo". Creo que eso es tontería. Simplemente, no creo que pueda ser cierto. La gente puede, por supuesto, decir cosas que otros no han visto. Pero la idea de que todos han estado completamente equivocados hasta este momento acerca de lo que él quería realmente decir... eso justamente resulta demasiado improbable para que pueda defenderse. Sin embargo, se sigue afirmando. No sé por qué Frege particularmente da lugar a esto. Esto no pasa con Russell. Ni siquiera pasa con Kant, ¿no es así?

FP: Sucede con Wittgenstein. Él parece sucitar a este tipo de cosas en particular.

\footnotetext{
3 Frege: Philosophy of Language fue seguida por The interpretation of Frege's Philosophy, Duckworth, Londres, 1981. Frege and Other Philosophers, Clarendon Press, Oxford, 1991; and Philosophy of mathematics, Duckworth, Londres. 1991.
} 
MD: Es perfectamente verdadero. Pues, Wittgenstein es mucho más oscuro que Frege, debido al modo en que escribió. Habitualmente deja librado al lector el ver la cuestión.

FP: Muchas de las observaciones de Wittgenstein están abiertas a interpretación. Hay muchas oraciones y párrafos que parecen contener observaciones desconectadas.

MD: Y las preguntas quedaron sin ser respondidas, y así en más. Usted tiene que preguntar: "¿Por qué este párrafo aparece en este punto? ¿Por qué él puso aquello en aquel lugar?" Por eso pienso que se hace más incomprensible. Creo también que estamos a un largo trecho de comprender a Wittgenstein. Quizás en tales argumentos emergerá la verdad, pero no creo que haya lugar para argumentos de ese tipo en el caso de Frege. Ciertamente, hay mucho espacio para argumentar en la evaluación de sus doctrinas. Pero, lo que ellas fueron, me parece bastante claro.

FP: Eso me lleva a otra pregunta sobre Wittgenstein. Usted ha dicho que ha comenzado su carrera filosófica considerándose a sí mismo como un seguidor de Wittgenstein, al menos hasta $1960^{4}$. Tengo tres preguntas con relación a eso. Para comenzar, ¿Qué significaba para usted en aquel tiempo ser un seguidor de Wittgenstein? En segundo término, ¿se embarcó usted en el estudio de Frege a lo largo de su vida adoptando una perspectiva filosófica particular que uno pudiese llamar wittgensteniana? Finalmente, ¿concibió usted que se podría considerar su trabajo sobre Frege, como opuesto al realismo, como una tentativa enteramente diferente de su propia perspectiva filosófica?

MD: Obviamente me embarqué en el estudio de Frege adoptando una perspectiva filosófica, debido a que nadie llega a un escrito filosófico sin alguna preconcepción. Pero, ciertamente no en forma consciente, en el sentido en el que uno podría decir: "Ahora voy a mirar a Frege desde el punto de vista de Wittgenstein", o algo semejante. No vi esto separadamente, y en el fondo no ha estado separado para mí, precisamente porque las preguntas de Frege, son en gran parte, preguntas. El estudio sobre el trabajo de Frege ha significado mucho para mí como punto de partida para pensar muchas cuestiones filosóficas. Por su puesto, cuando usted escribe sobre un escritor en particular, tiene que hacer un buen trabajo de exposición, pero como usted sabe, especialmente en el primer libro, traté de hacer una plataforma, para continuar discutiendo un rango de cuestiones filosóficas. Hay mucho en ese libro que no trata para nada de Frege, pero que justamente arranca de allí.

\footnotetext{
${ }^{+}$Truth and Other Enigmas, Harvard University Press, Cambridge, Mass., 1978. p. xii.
} 
FP: Esta fue una de las críticas de Hans Sluga ${ }^{5}$.

MD: Fue una de sus críticas, y tengo que admitir que había algo de justicia en ellas, a pesar de que disiento con algunos detalles. No pienso que el tipo de antecedente histórico que él trata de asignar a Frege sea del todo convincente. Pero, es perfectamente verdadero que cuando escribí el primer libro, no estaba tomando suficientemente en consideración la situación en la cual el mismo Frege estaba. Creo que esto debe hacerse. Yo estaba pensando más sobre los vínculos entre su trabajo y lo que sucedió posteriormente. Pienso que uno debe preguntarse a sí mismo cuando lee a un filósofo: "¿Cómo se formulaba él problemas en aquel momento, dada la clase de cosas que otra gente estaba diciendo por entonces?".

FP: Con respecto a Frege $y$ Wittgenstein, usted ha dicho que la concepción de Wittgenstein del carácter social del significado, del significado como uso, fue anticipada por la idea de Frege de objetividad del sentido ${ }^{6}$. ¿No es éste un modo de mirar a Frege desde un punto de vista de tipo wittgeinsteniano?

MD: No estoy seguro. El énfasis de Frege es muy fuerte allí, respecto de la comunicabilidad de los pensamientos (Gedanken), y sobre el hecho en que éstos son comunes para todos nosotros.

FP: Y aquí se establece en una firme oposición con la incomunicabilidad de las representaciones (Vorstellungen).

MD: Correcto. No hay en Wittgenstein el mismo tipo de rechazo de la idea de incomunicabilidad de los estados mentales. Lo que se podría decir sobre Frege es que existe un énfasis sobre la comunicabilidad de algo accesible a todos, pero no existe una detallada indagación sobre esto. Él no discutió para nada cómo es que podamos todos asignar el mismo sentido a nuestras oraciones.

FP: Tampoco brindó ninguna explicación acerca de lo que es la comprensión (grasping) real de los pensamientos. Simplemente, existe, por decirlo así, el acto desnudo de la comprensión.

MD: Correcto. Es simplemente un hecho.

FP: ¿Así que usted piensa que la idea de Wittgenstein es un modo de hacer efectiva la intuición de Frege?

\footnotetext{
${ }^{5}$ Sluga, H., Gottlob Frege, Routledge and Kegan P., London, 1980.

6 "What is the Theory of Meaning? (II)", Truth and Meaning -Esscrys in Semantics, Evans, G. y McDowell, eds., Clarendon Press, Oxford, 1976, o. 135: "La tesis de Frege de que el sentido es objetivo es implícitamente, por lo tanto, una anticipación (con respecto a este aspecto del significado que constituye el sentido) de la doctrina de Wittgenstein acerca de que el significado es uso (o de una de las familias de doctrinas así expresadas) [...]."
} 
MD: Pienso que uno podría, seguramente, verlo de ese modo. Es difícil saberlo. Obviamente, estaba profundamente influenciado por Frege. Usualmente, cuando critica a Frege, veo su lado negativo. No porque Frege haya estado siempre en lo correcto, y Wittgenstein se equivocara, sino simplemente porque es bastante rudo cuando lo critica. No sé por qué. Obviamente, gran parte de la influencia no se muestra en la superficie. Él no se refiere siempre explícitamente a Frege y no siempre lo reconoce, cuando debería. Creo que probablemente la génesis de aquellas ideas puede haberse dado leyendo a Frege. No lo sé con seguridad.

FP: Hay otro punto de su lectura de Frege que resulta destacable: el énfasis sobre la idea de Frege de que comprender el significado de una oración, esto es, el pensamiento expresado en una oración - es conocer sus condiciones de verdad, o si estas condiciones son o no satisfechas. Si no estoy equivocado, Frege defiende explícitamente esta concepción únicamente una vez, en Grundgeset$z e, \S 32^{7}$. Pero usted ve en este punto particular uno de los pilares del realismo de Frege, y su propia argumentación en contra del realismo está en el fondo explícitamente dirigida en contra de la llamada teoría de la verdad-condicional del significado. ¿Piensa usted que éste fue efectivamente un interés central de Frege?

MD: Absolutamente, pienso que se relaciona muy estrechamente con su oposición a la intrusión de la psicología en la lógica. Sólo basta con considerar lo que dice en Grundlagen sobre las definiciones psicologistas ${ }^{8}$. Cuando no se puede pensar en cómo definir un concepto matemático básico, se lo define en términos de las operaciones mentales necesarias para aprehender el concepto. Lo que él dice acerca de esto es: usted no puede usar tal definición para probar algo. Estoy de acuerdo con que la apreciación no se refiere directamente a las condiciones de verdad. Pero sólo píenselo: ¿Cuándo puede usted usar una definición para probar algo? Precisamente, cuando aquella le dice bajo qué condiciones una oración, que contiene el término definido podría ser verdadera. Si hace esto, o si ayuda a hacerlo, entonces usted puede ser capaz de usarla para probar que alguna oración particular es verdadera. Por eso pienso que esto es fundamental en Frege.

\footnotetext{
${ }^{7}$ Frege, G., Grundgesetze der Arithmetik, Begriffschriftlich abgeleitet, Band I; H. Pohle. Jena, 1893. Traducción al inglés del prefacio, introducción y § 1-52 por Furth, M. En, The Basic Lavs of Arithmetic: Exposition of the System; University of California Press, Los Ángeles, 1964. Este es el texto relevante de Frege: "Todo [...] nombre de un valor de verdad expresa un sentido, un pensamiento [drückt einen Sinn, einen Gedanken aus]. Nombrando nuestras estipulaciones, está determinado bajo qué condiciones [Bedingungen] el nombre denota [bedeute] la verdad. El sentido de este nombre -el pensamiento- es el pensamiento de que estas condiciones se satisfacen [daß diese Bedingungen erfüllt sind].

${ }^{8}$ Frege, G., Die Grundlagen der Arithmetik. Eine logisch-mathematische Untersuchung über den Begriff der Zahl, W. Koebner, Breslau, 1884. English translation by Austin J. L. Blackwell, B., The Foundations of Arithmetic- A logico-mathematical enquiry into the concept of number. Oxford, 1950. Ver en particular, Introducción, pp. iii $^{\mathrm{e}}, \mathrm{vi}^{\mathrm{e}}$, viii ${ }^{\mathrm{e}}, \mathrm{ix}^{6}, \mathrm{y}$ Parte II. $§ 26.27$.
} 
Usted ha mencionado también la cuestión del realismo vs. antirealismo. Lo que es muy notable en Frege es que él siempre se cuida de decir que las condiciones de verdad tengan que ver con el modo en que nosotros reconocemos el valor de verdad. Muy frecuentemente hay una advertencia real. Por ejemplo, cuando sostiene que los predicados deberían siempre ser definidos y que debería siempre ser determinado para cualquier objeto, si es que queda incluido o no bajo un concepto. (Y usualmente agrega: nosotros podemos no ser capaces de determinarlo, a pesar de que lo está,

como si fuese objetivamente determinado). La realidad lo determina; o algo así. Por eso el rechazo a tomar esto en los términos en que Wittgenstein lo hubiese realmente tomado -en los términos de lo que nosotros podemos hacer- es efectivamente bastante consciente.

\section{Inconsistencia, holismo, armonía e intuicionismo}

FP: Permítame volver a Wittgenstein. Mi próxima pregunta se refiere a cómo deberíamos leer el famoso lema 'El significado es el uso' y determinar cuáles son las implicaciones filosóficas que puede haber ${ }^{9}$. Este es un gran problema y tiene que ver, una vez más, con la idea de ser un wittgeinsteniano vs. no ser un wittgeinsteniano, en el sentido siguiente. Mucha gente siente que ninguna interpretación del famoso lema de Wittgenstein pueda alguna vez conducirnos, como usted asevera que lo hace, a una revisión de las leyes de la lógica clásica. No estoy hablando aquí únicamente de la gente interesada en lo que Wittgenstein realmente quiso decir. Me parece que mucha gente quiere resistirse a la idea de que algo tan 'obvio', como "El significado es el uso" pueda conducir a algo drástico. ¿Por qué piensa usted que conduce a ello?

MD: Trataré de responder. Fundamentalmente, porque no acepto el holismo al modo en el que creo que Wittgenstein lo hizo, o al menos en el que se le atribuye. Usted conoce la famosa concepción de que la filosofía no puede alterar nada por completo, que únicamente puede describir, etc. En particular, él tenía la idea de que no se puede alterar la práctica lingüística, y cayó en el absurdo de que la filosofía no podría alterarla, aún cuando esta práctica se hubiese

\footnotetext{
" Ver Wittgenstein, Philosophische Untersuchungen/ Philosophical Investigations, English translation by Ascombe, G. E. M Basil Blackwell, Oxford, 1958, Part I, $\S 43$ : 'For a large class of cases though not for all- in which we employ the word "meaning", it can be defined thus: the meaning of a word is its use in the language (Die Bedeutung eines Wortes ist sein Gebrauch in der Sprache).' [ En una gran clase de casos - pero no en todos- en los que empleamos la palabra "significado", puede ser definido por ende: el significado de una palabra es su uso en el lenguaje]. Ver también Philosophical Investigations, Part I, $\S \S 120,138,190,432$, y las páginas abiertas de The Blue and Brown Books, Basil Blackwell, Oxford, 1958.
} 
mostrado inconsistente o condujera a una contradicción. Uno tiene que aceptar las contradicciones como un hecho.

FP: Pero nuestra práctica lingüística ciertamente podría ser inconsistente.

MD : Tarski creyó que esencialmente, lo era

FD: La práctica lingüística real es usualmente inconsistente.

MD: Bueno 'práctica lingüística real' ... ¿Qué es lo que uno quiere decir exactamente con esto? Ciertamente, no puede ser parte de una práctica que la gente, justamente, afirme contradicciones. Si usted quiere decir que una práctica es contradictoria, tendrá que decir que hay principios generales que la gente sigue y que puede reconocer como tales. Quiero decir con esto, que ellos podrían reconocer que siguen estos principios. Si los presionamos, reconocerían también cuáles los conducen a contradicciones. El punto es que los podríamos presionar a hacer esto.

FP: Entonces la gente se contradice a sí misma. ¿No es ésta una práctica? ¿Por qué no decir simplemente que ellos están involucrados en la práctica de la contradicción?

MD: Se podría decir eso. Pero luego tendría que cualificar su afirmación y admitir que ellos pueden también reconocer que lo que han dicho requiere de alguna revisión. Hay una distinción entre un individuo que se contradice a sí mismo y que admitiría el error y sus causas, y lo inconsistente del lenguaje mis$m o$, que es lo que preocupaba a Tarski sobre los lenguajes naturales. ¿Qué significa que hay principios generales que gobiernan el uso de los lenguajes que todos reconocerían y que son de tal tipo que las personas, si fuesen presionadas, admitirían que los conducen a una contradicción? Esas son las paradojas. Cuando son enfrentadas a paradojas, las personas no saben qué hacer, porque han sido conducidas a una contradicción por pasos que parecen absolutamente obligatorios. Por eso simplemente se apartan de ellas. Por supuesto, luego los filósofos comienzan a preocuparse sobre esto.

El punto importante en nuestra discusión sobre el holismo es el siguiente: Wittgenstein pensó - y yo estuve completamente en desacuerdo con esta visión- que nada en la práctica lingüística y en particular en el uso de formas de inferencia requiere de una justificación o puede ser criticado. Si es la práctica lo que es absurdo, entonces esa justificación es suficiente. No se requiere de ningu- 
na justificación además de eso. Ahora, me parece que esto está equivocado porque las inferencias no son cosas que estén separadas del resto del lenguaje. Una inferencia no es justamente un juego tal como un crucigrama, que no afecta ninguna cosa más. Conduce a aserciones y conclusiones, y aquellas conclusiones pueden contener constantes lógicas. Por eso uno debe preguntarse: "¿Cómo son usadas? ¿Cómo reaccionamos a estas aserciones? ¿Qué consecuencias deberían extraerse de ellas? etc.

Me parece que existe la posibilidad de un desacuerdo entre el modo en que razonamos y el modo en el que usamos las conclusiones a las que arribamos por el razonamiento. Un proceso de razonamiento tiene que ser justificado sobre la base de que conduce a cosas que justificadamente podemos sostener de acuerdo a los significados que les asignamos.

FP: $Y$ en particular, al significado que asignamos a las constantes lógicas.

MD: Correcto. Por eso, existe algo así como un requerimiento de consonancia, entre partes diferentes de una práctica lingüística, lo cual es algo extremadamente complicado y que no nos da derecho a decir: 'Bueno, nosotros simplemente razonamos de ese modo, eso es lo que llamamos "razonamiento" y esto es así'.

FP: Por eso, es el requerimiento de armonía el que impone el rechazo del holismo y lo que nos fuerza a leer 'El significado es el uso' como indicándonos una revisión de ciertos esquemas de razonamiento, tal como aquellos basados en las leyes de la lógica clásica. Eso es muy anti-wittgensteiniano.

MD: Ese es el aspecto en el cual yo discrepo completamente con Wittgenstein. Yo pienso que no ha habido ninguna justificación de su expresión respecto de que la filosofía no puede interferir para nada. Nuestra práctica lingüística puede estar equivocada, tal como nuestro comportamiento puede estar errado o ser irracional. La filosofía tiene el derecho de señalar esto.

FP: ¿Piensa que los esquemas clásicos de razonamiento y leyes de la lógica clásica son realmente inconsistentes y nos conducen a contradicciones?

MD: No pienso que sean completamente inconsistentes. No pienso que nos conduzcan a algo tan malo como la contradicción. Pienso que ellos conducen, o pueden conducir, a la desarmonía de la que estaba usted hablando. Al usar ciertos esquemas de inferencia, somos conducidos a afirmar cosas que actual- 
mente no tenemos derecho a afirmar, dado el significado que asignamos a nuestras palabras.

FP: Vamos a considerar un caso estándar. Supongamos que alguien use la regla de la eliminación de la doble negación, es decir, infiere p de $\neg \neg \mathrm{p}$. Un intuicionista rechazaría esta inferencia al considerarla inválida. Pero, ¿qué es lo que está equivocado en esta ley? ¿Debe ser que no podemos afirmar $\mathrm{p}$ de $\neg \neg \mathrm{p}$ ? ¿Debe ser que no podemos afirmar p sobre las bases de $\neg \neg$ p. ¿Pero por qué no puede $\neg \neg \mathrm{p}$ constituir fundamento suficiente para $\mathrm{p}$ ?

MD: No es un fundamento suficiente en sí mismo. Por supuesto, hay muchos casos en los cuales está perfectamente bien, y esos casos incluyen todos aquellos en los cuales podemos realmente decidir la cuestión. Pero, en general, cuando es algo para lo cual no tenemos medios de decidir, entonces, existe un problema. Todo depende de cómo entendamos la negación. Si, como naturalmente hacemos, lo entendemos de tal modo que es suficiente, en orden a afirmar la negación de un enunciado $\mathrm{p}$, mostrar que no se podría estar en la posición de afirmar p, luego, el hecho de que no se pueda estar en posición de afirmar la negación misma, ciertamente, no garantiza que se esté en posición de afirmar exactamente la oración $p$.

FP: Pero esto constituiría un fundamento necesario para la aserción, si pudiésemos en el fondo determinar el valor de verdad de $\mathrm{p}$ ?

MD: Correcto, de otro modo simplemente obtendríamos algo más débil. La ilusión proviene de una imagen que tenemos de una determinada realidad, la cual no podemos ser capaces de observar, pero que debe no obstante ser fijada de un modo o de otro. ¿No es falso? Bueno, luego debe ser verdadero. Es simple. La que usamos, es una imagen que se nos impone psicológicamente.

Mire, esto no tiene exactamente que ver con las reglas de inferencia, pero tiene mucho que ver con las imágenes realistas. Hay una creencia fuertemente predominante en el determinismo. Voy a hacer una referencia a la mecánica cuántica. Ese es otro problema. Quiero decir, es solo otra razón de por qué las personas no deberían pensar en el determinismo. Pero, olvidémonos de la mecánica cuántica. Sólo pensemos en los sistemas caóticos. Se ha me dicho que los sistemas caóticos deterministas sostienen que si se tiene las condiciones iniciales precisas, luego los estados consecuentes de los sistemas, estarían completamente determinados. El problema es, que no podemos predecirlos porque de ningún modo podemos tener las condiciones precisas, y las pequeñas variaciones producirán una gran variación luego, Por eso se supone que es impredecible, y no 
obstante, determinista. Ahora, hablar de los sistemas que son deterministas es simplemente asumir que existen valores precisos de las condiciones iniciales de las cantidades dadas por los números reales. Pero, eso simplemente significa la imposición de una clase de imagen matemática, la matemática del continuo de la realidad, la cual realmente no condice con nuestra experiencia de ningún modo. Todo el mundo está constantemente remarcando que, cuando medimos, no solamente medimos con un cierto grado de precisión, y todo eso, etc. Si usted no asume que estas cantidades tienen en aquel sentido absolutamente magnitudes determinadas, para empezar con algo, usted no tiene ningún fundamento remanente de determinismo. Afirmar que los sistemas están determinados es simplemente hacer observaciones matemáticas.

FP: Es como si sólo fuera una característica de las matemáticas.

MD: Esto es correcto, la hipótesis que subyace es que todas estas cantidades tienen magnitudes absolutamente determinadas dadas por números reales.

FP: Esto es lo que la llamada 'teoría del valor oculto' parcialmente significa. MD: Exactamente. Es justamente algo impuesto por el modo de pensar.

FP: Este fue el punto de vista de Einstein.

MD: Pero, esa fue la respuesta para algunos problemas específicos de la mecánica cuántica. No estoy hablando de eso. La mayoría de los físicos aceptan el continuo clásico como un buen modelo de la realidad física, pero pienso que harían mejor si usasen el continuo intuicionista. Siempre se está avanzando en una progresión, pero nunca arribamos a los valores determinados.

FP: Vamos a hablar acerca de Wittgenstein y la relación entre Wittgenstein y el intuicionismo. Una cosa que a la gente no le gusta mucho sobre el intuicionismo es el tipo de subjetivismo y aún del solipsismo filosófico, que lo acompaña. O, con lo que el intuicionismo de Brower se comprometió. ¿Piensa usted que la visión wittgensteinana del carácter social del significado provee un camino de salida de aquel? Supongamos que "el significado es uso" conduce en el fondo a una revisión de la lógica clásica. ¿Si aceptamos esa interpretación de esa parte de la filosofía tardía de Wittgenstein, podríamos realmente sacar al intuicionismo fuera del solipsismo, fuera de ese tipo de solipsismo con el cual está usualmente asociado?

MD: Creo que sí. Por supuesto, Brower parece haber sido un solipsista genuino. Pienso que él verdaderamente no creyó en otra persona. Tomemos 
como ejemplo el lenguaje de datos de los sentidos, que es en sí mismo un lenguaje solipsista. Si hubiera un tal lenguaje, sería sumamente trabajoso ir desde allí hacia un lenguaje físico objetual. Pero el caso matemático es completamente diferente. El contraste con la matemática es impresionante y Brower, por supuesto, está completamente equivocado acerca de la incomunicabilidad de las estructuras matemáticas. Lo que es sorprendente sobre las matemáticas es justamente su comunicabilidad. No hay nada en una idea matemática que no pueda ser comunicado. La cosa más interesante de esto, es que no hay que hacer nada, en el sentido de que si usted tiene una descripción de una teoría matemática en términos de construcciones que los matemáticos individuales hacen en su mente, usted no tiene que hacer virtualmente nada para transformar aquello en una descripción de las construcciones que pueden ser comunicadas de un matemático a otro. ¿Por qué? Porque la teoría de Brower puede ser convertida sin algún cambio, excepto en el asunto de fondo, en algo así como una teoría matemática comunal. No podría suceder en ningún otro campo del discurso. En el caso del mundo físico, va a haber una enorme brecha entre el mundo que todos nosotros habitamos y el mundo que yo observo. Pero en el caso de la matemática no hay tal brecha, y por eso es que el solipsismo, que coincido absolutamente fue parte de su filosofía y la motivó, realmente no tiene importancia.

\section{Austin, Ryle y Carnap}

FP: ¿Puedo volver a Wittgenstein? Usted afirmó en el Prefacio de Truth and other Enigmas, que el tipo de trabajo que llevó a cabo Wittgenstein, -al menos, supongo. en Investigaciones Filosóficas-, lo inoculó contra la influencia de Austin. ¿Cómo piensa usted que el trabajo de Wittgenstein ayuda a oponerse al del tipo de argumentación "caso-paradigma" de Austin y a los modos deliberadamente no sistemáticos de tratar con el lenguaje, es decir, a oponerse a la filosofía del lenguaje ordinario, que dominó Oxford en los comienzos? Más aún, ¿Piensa que la filosofía analítica debería o podría ser sistemática?

MD: La observación que hice sobre Austin fue sólo una observación histórica, como si fuera sobre mí mismo. Es verdad que esta oposición al sistema es común en Wittgenstein y en la filosofía del lenguaje ordinario de Austin. La idea que usted tiene que operar con las cosas pieaza por pieza. Pero lo que yo pienso como la gran diferencia entre Wittgenstein y al menos lo que Austin profesaba, o lo que enseñaba, fue que Wittgenstein siempre comenzaba con problemas filosóficos y acometía contra ellos, mientras que Austin pensó que éstos eran debidos a confusiones, malentendidos en nuestro propio lenguaje, incorrecciones en él. Wittgenstein ciertamente pensó lo mismo que Austin, que había muchísimo que hacer con el lenguaje, pero él comenzó con los problemas, mien- 
tras que Austin, verdaderamente enseñó -no sé si esto es verdadero de su propia práctica- que debemos olvidar los problemas filosóficos. Debemos comenzar mirando las palabras y cómo son usadas, hacer análisis muy precisos de estos y así sucesivamente, sin tener en cuenta qué problemas filosóficos hay; y luego, se producirá un milagro y todos los problemas filosóficos serán disueltos. Esto es lo que lo que mayormente me parece tan destructivo de la reflexión filosófica así entendida. La motivación de la actividad completa proviene de las complejidades en las que uno se introduce cuando comienza a pensar sobre la voluntad humana, o el tiempo o cualquier cosa. Y enseñar a la gente a dejar de prestar atención a estas cosas, bien...

FP: Existe otra tradición en la filosofía analítica. Estoy pensando en la influencia de Carnap en los EEUU. Carnap fue un filósofo sistemático, y tuvo una enorme influencia sobre Reichenbach, Quine, Goodman, Putnam, etc. Existen generaciones completas de filósofos norteamericanos que concibieron la filosofía tal como Carnap pensó que era, o que lo tomaron como modelo, y para Carnap la empresa filosófica era la construcción de un sistema. ¿Piensa usted que él estaba más cerca de la visión correcta de lo que sería una empresa filosófica? Por supuesto, él tuvo aquí escasa influencia.

MD: Y eso es debido a Ryle. Permítame una última cosa acerca de Austin. Yo siempre pensé que Austin era ciego sobre los tópicos de la reflexión filosófica. Fue un hombre muy inteligente, pero siempre pensé que su influencia fue extremadamente nociva. Y debido a Ryle, no tuve por entonces esa visión de él. Gradualmente fui llegando a ello, pero no la tuve en aquel momento. Por el contrario, creí, o probablemente creí, mucho de lo que Ryle dijo. El estaba tremendamente en contra de Carnap. Consideraba a Carnap como el peor filósofo, como cometiendo errores triviales, y por aquella razón pasó mucho tiempo antes de que yo leyera algo de Carnap y lo tomara seriamente. He madurado, por así decirlo, estudiando filosofía en Oxford cuando Ryle era el rey. Él tuvo una tremenda influencia. Austin vino un poco más tarde. Creí estar convencido de que no había ninguna necesidad de prestar atención a Carnap, simplemente porque Ryle se burló de él. Por eso, es bastante diferente para mí de lo que es para otras personas, para las cuales Carnap fue una autoridad importante.

FP: Basta sólo con considerar su influencia sobre Quine o Goodman.

MD: Eso es verdad. The Structure of Appearance ${ }^{10}$, que el fue el primer libro de Goodman, fue un esfuerzo, un intento de hacer el mismo trabajo que el

\footnotetext{
${ }^{10}$ p. xii
} 
de Logische Aufbau. Pensé, y realmente aún lo pienso, que es una empresa completamente equivocada ${ }^{11}$. Pienso que el punto de vista de Wittgenstein de que no hay ninguna tesis filosófica que la filosofía pueda verdaderamente sostener, $y$ que todo lo que ella puede hacer es recordarle a uno cosas que ya conoce bien, está equivocada. Hay teorías para ser construidas. Aunque no me impresionan bien las teorías de Carnap. Hay algo un tanto estéril en ellas. Por eso, para mí la revuelta de Quine es muy comprensible. ¿Cómo podría expresarlo? ¿Conoce la historia sobre el irlandés? Alguien ha perdido su camino y le pregunta a un irlandés: ¿Conoce como puedo llegar a Dublín? El irlandés piensa un ratito y dice: si estoy yendo a Dublín no debería partir de aquí." Me parece que resulta una lástima empezar por Carnap.

FP: Eso puede ser cierto, pero hay muchos problemas que se pueden encontrar en Carnap, por ejemplo, en el largo artículo "Testability and Meaning", que están verdaderamente muy cerca de un tipo de cuestiones de las que usted mismo se ha preocupado ${ }^{12}$. Estoy pensando en particular en la teoría verificacionista del significado o del modo en el cuál él trata de enmendarla y reemplazar la noción de verificación por una menos fuerte de confirmación gradual, entendida en términos probabilísticos. Estoy también pensando en su negación de la idea ingenua de que los enunciados que no pueden ser verificados no tengan significado, un signo seguro de que algo estaba mal con el criterio verificacionista de la significación cognoscitiva. Todo lo que concierne a esto estaba muy cerca de los problemas fundamentales del debate realismo versus anti-realismo, como usted lo concibe.

MD: Probablemente eso es verdadero. Debe ser un efecto retardado de las enseñanzas de Ryle el que no le haya prestado atención a Carnap.

\section{Filosofía analítica, su historia y la tesis primordial}

FP: Vamos a dejar de lado a Carnap. Permítaseme pasar a otra cuestión. Recientemente usted ha mostrado cierto interés por la historia de la filosofía. Usted afirma al comienzo de los Origins of the Analytical Philosophy, que la

\footnotetext{
${ }^{1}$ Carnap, R. Der logische Aufbau del Welt, Weltkreis-Verlag, Berlín, 1928; English translation by Berkeley, R.A., The Logical Construction of the World, University of California Press. Berkeley, 1967. Goodman,N., The Structure of Appearance, Harvard University Press, Cambridge, Mass., 1951. Véase la reseña de Dummett sobre este último en Truth and Other Enigmas, Cap. 3, pp. 29-37. ${ }^{12}$ Carnap, R., Testability and Meaning, Philosophy of Science, Vol. 3 (Oct.1936), pp. 419-71 [sec. IIII]; vol.4 (Jan. 1937), pp. 1-40 [sec. IV].
} 
filosofía analítica debe compreder su propia historia ${ }^{13}$. Presumo que esto fue estimulado por las críticas de Sluga sobre su primer trabajo.

MD: Posiblemente sí. Indirectamente. Es decir: las observaciones de Sluga me convencieron un tanto de que yo no le había prestado suficiente atención a los antecedentes históricos. Pero luego, como ya he dicho, no me habría impresionado mucho. En particular, tenía una impresión de desilusión por su rechazo a prestar alguna atención a Husserl. En el libro sobre Frege él dice que sería interesante hacer una comparación entre los dos, pero, ésta no aparece en el libro. Me parece que si se va a escribir un libro sobre Frege y su escenario histórico, esto es precisamente lo que se debería hacer. No resulta demasiado fructífero aquello sobre Lotse y demás. Pero no fue sólo como una respuesta a Sluga. Fue también por German Philipse, un filósofo holandés que estuvo en Oxford en 1982 o 1983 que quería dar un seminario sobre las Investigaciones Lógicas de Husserl. Se contactó conmigo, en parte porque era un visitante y no sabía si alguien podía venir, y dar por sí mismo un seminario, o esto no se permitía. Me ofrecí a darlo con él. Como consecuencia, claro, comencé a leer mucho sobre las Investigaciones y adquirí mucho interés. Por eso fue una combinación. La otra motivación fue responder a las cuestiones que Sluga había fracasado en responder.

FP: ¿En qué consiste el interés filosófico por una comprensión de aquel tipo, la comprensión de la historia de la filosofía analítica, aparte de la historia general o el interés cultural? La vasta mayoría de filósofos analíticos piensa que esto cae enteramente fuera del interés filosófico.

MD: Sí. Pero mire; en los comienzos tempranos de la centuria, digamos por la época en que Husserl publicó las Investigaciones Lógicas, no existía aún la fenomenología como escuela. No existía aún la filosofía analítica como escuela. Había un montón de corrientes allí y se tendría que colocar a Frege y a Husserl bastante cerca uno del otro, y aún su herencia divergía ampliamente. Hay una pregunta muy interesante que me parece puede aportar comprensión. ¿Por qué ellos tenían puntos tan divergentes? Otro modo en el que podría expresarlo es este. En la tradición analítica misma, existe ahora un número de personas Gareth Evans fue uno de los primeros- que rechazan lo que una vez denominé el teorema fundamental de la filosofía analítica, la prioridad del lenguaje sobre el pensamiento.

\footnotetext{
${ }^{13}$ El texto original de la serie de Conferencias dadas en la Universidad de Bolognia en 1987 apareció en Lingua e Stile Anno xxiii.1988.pp. 3-49, 171-270. Una versión revisada fue publicada luego como Origins of Analytical Philosophy, Duckworth. London 1993. Yo (F. Pataut) he reseñado esa edición.
} 
FP: La tesis de la prioridad.

MD: Sí, la tesis de la prioridad. Sin embargo, ellos están dentro de la tradición analítica. Supongo que Evans nunca leyó una palabra de Husserl en su vida entera. En su libro, Russell, Frege y Moore fueron los pilares ${ }^{14}$. Hay otra gente ahora. Christopher Peacocke es otro. Eso nos lleva a la pregunta: '¿Qué es esencial en la filosofía analítica?' En un comienzo se podría haber dicho que era la tesis de la prioridad. Todos ellos la aceptaban. Pero eso ya no es más verdadero. ¿Son todas estas personas filósofos analíticos? Es perfectamente claro que lo son, porque el tipo de análisis que ellos prosiguen es muy similar, o al menos se desarrolla desde una teoría fregeana del significado, una semántica fregeana, o algo así. Por eso la cuestión de determinar qué es esencial para la filosofía analítica es en el fondo una pregunta muy interesante. Pero, ¿Cómo se puede entenderla a menos que se retrotraiga a sus orígenes? ¿Qué distingue este tipo de filosofía de otras? ¿Qué produce exactamente que surja la divergencia? Por eso pienso que hay mucho trabajo por hacer.

Otra cosa que no discutí para nada en el primer libro, pero de lo cual pienso que se puede extraer mucha claridad, es el hecho de que no entendemos para nada la interacción entre Wittgenstein y el Círculo de Viena. A causa del Tractatus. Es que Wittgenstein veneraba a Frege, pero es escuela-de-Russell mucho más que escuela-de-Frege. Fue escrito en la atmósfera de Cambridge, ¿no es así? Los problemas que él había estado pensando eran problemas que Russell, Ramsey, etc. habían estado pensando. Y luego, causa un gran impacto sobre gente completamente diferente, en una atmósfera completamente diferente, Viena. ¿Qué sucedió exactamente? ¿Cuál fue la relación entre Wittgenstein y esas personas? Yo realmente no la comprendo en absoluto, y me parece que si lo hiciésemos, aprenderíamos muchísimo, no sólo desde el punto de vista histórico, sino filosófico.

FP: Usted también afirma al comienzo del libro, que no está interesado en las relaciones causales entre autores y teorías, sino en la posteridad de ideas que estaban en l'air du temps en el cambio de siglo, ideas que también se encuentran en autores que pertenecen a la tradición analítica como Brentano y Hus$\operatorname{serl}^{15}$. En un punto, usted afirma que lo que le interesa es la legítima posteridad

\footnotetext{
${ }^{14}$ Las variedades de la referencia, editado por J. McDowell. Clarendon Press. Oxford, 1982. También por Gareth Evans, Collected Papers, Clarendon Press. Oxford, 1985.

${ }^{15}$ Origenes de la Filosofia Analitica, pp. 2-3.
} 
de estas ideas ${ }^{16}$. ¿Había algún intruso, gente que ilegítimamente afirmaba pertenecer a la tradición analítica, pero que realmente no pertenecía a ella?

MD: Esa es una muy buena pregunta. Las únicas personas que se me ocurren en este momento como intrusas son personas de varios tipos, que piensan que la filosofía está acabada de un modo o de otro. Entre ellos se encuentran muchos de los así llamados seguidores de Wittgenstein. Por supuesto, están Baker y Hacker, quienes piensan que realmente no hay más problemas filosóficos que resolver ${ }^{17}$. Una vez que se ha alcanzado el nirvana, como ellos lo han hecho, se ve que toda discusión filosófica está encadenada al sinsentido. Todo lo que se puede hacer es dejar de lado la historia de esto y señalar los diferentes tipos de sinsentido, de los que esta gente estaba hablando. Es justamente la historia de los seudoproblemas y de las series de soluciones sinsentido propuestas para resolverlos. Eso es todo lo que hay. Rorty, en los Estados Unidos, desde una perspectiva levemente diferente, predica esencialmente la misma doctrina.

FP: Esto ha sido predicado en el continente desde hace mucho tiempo.

MD: ¿Es verdad? ¿Quién lo hace?

FP: Derrida, por ejemplo. Pero también, y de modo más general, ha sido predicado por gente que está convencida de que existe una discontinuidad fundamental entre los problemas filosóficos tal como aparecen en los diferentes estadios de la historia, o más aún, entre los diferentes constructos de estos problemas. En este caso, la doctrina parece ser una consecuencia directa de una concepción historicista de la filosofía, más que de un credo filosófico, gente que juzga que las soluciones de problemas tradicionales están a-priori condenadas al fracaso.

MD: Pero Derrida no pretende estar en la tradición analítica.

FP: Pero la influencia continental es muy grande en Rorty. $\mathrm{Y}$ a través de gente como Rorty, curiosamente, también sobre Putnam.

\footnotetext{
${ }^{16}$ Op. cit., p. 3: "Voy a hablar acerca de las direcciones a las que conducen varias ideas filosóficas, y cuáles fueron los desarrollos legítimos de ellas, sin complicarme mucho sobre quién leyó los libros de quien o sobre si X derivó una cierta idea de Y o arribó a ella independientemente".

${ }^{17}$ Baker y, G.P., Hacker, P.M.S., Wittgenestein: Understanding and Meaning, Vol. I de Basil Blackwell, Oxford, 1980; Vol. 2: Wittgenestein: Rules, Grammar and Necessity, Basil Blackwell, Oxford, 1985.
} 
MD: Putnam rechaza mucho de lo que afirma Rorty, pero está un poco influenciado por él. De acuerdo, vamos a clasificarlos a todos ellos como intrusos.

FP: Entonces, ¿cómo podría identificarse la tradición analítica? Parece ser una empresa muy ardua. No podemos hacerlo diciendo que existe un grupo de posiciones que todo filósofo analítico debería sostener justamente porque son filósofos analíticos. (Así es, cambiando de tema, como ciertas personas conciben las cosas con relación a los filósofos analíticos continentales, como que todos ellos son positivistas de un modo u otro.) No podemos hacerlo, por así decirlo, por contenidos; pero tampoco podemos hacerlo por los métodos. No existe tal cosa como un simple método que todos los filósofos analíticos compartan cuando ellos atienden a un problema particular. Entonces, ¿cómo deberíamos hacerlo? En Origins of Analytical Philosophy, usted adopta un punto de vista muy fuerte y restrictivo sobre esta cuestión cuando sostiene que únicamente un análisis filosófico del lenguaje puede conducirnos a un análisis filosófico del pensamiento $^{18}$. Me parece que si tomamos esta vía, el trabajo de Gareth Evans realmente no formaría ya más parte de la tradición. Tal vez todavía pertenecería, pero sólo de modo marginal. cierto?

MD: Pero, históricamente es muy claro que él pertenece a ella ¿no es

FP: Históricamente pertenece, y este es precisamente el punto al que quería llegar. Podemos mirar a este problema desde un ángulo diferente. Pensemos, por ejemplo, el modo de explicación que Nelson Goodman da acerca de lo que comprende el nominalismo (su propio y particular tizón). Él no está particularmente embarcado en expresar lo que los individuos son. (comparto que él eventualmente hace eso), está primariamente embarcado en explicar en qué consiste describir el mundo como compuesto de individuos ${ }^{19}$. Uno podría decir: 'Bien, ese es el procedimiento típico del operar analítico'. La cuestión metafísica per se se pospone hasta que la cuestión lingüística sea propiamente entendida o resuelta, o quizá hasta que hayamos encontrado una formulación satisfactoria de la cuestión lingüística. Podríamos encontrar muchas otras instancias.

\footnotetext{
${ }^{18}$ Op. cit. P.4 "Lo que distingue a la filosofía analítica, en sus diversas manifestaciones, de otras escuelas es la creencia, primero, de que dar cuenta filosóficamente del pensamiento puede ser alcanzado a través de dar cuenta filosóficamente del lenguaje, y segundo, que sólo (énfasis de FP) puede conseguirse dar cuenta de ese modo".

19 Véase, por ejemplo, Goodman, N., "A world of Individuals", reimpreso en Problems and Projects, Bobbs-Merrill, Indianapolis and New York, p. 159.
} 
Pero permítaseme retornar a Evans y al análisis de los pensamientos singulares que propone en su "Understanding Demostratives", el cual, de diversos modos, se funda en un rechazo implícito a la tesis que usted toma como la tesis fundamental de la filosofía analítica. Evans supone que "adscribir un sentido fregeano a un término singular, es afirmar que existe un modo particular en el cual su referente debe ser pensado (como el referente) si se quiere entender el término"20. Si seguimos la sugerencia de Evans, nuestra explicación irá desde el pensamiento al enunciado y al término. Vamos a comenzar por explicar qué es tener o abrigar un pensamiento sobre un objeto particular y después, vamos a caracterizar el significado de un enunciado que contiene una ocurrencia de un término singular que tiene el objeto como su referente, en términos de una expresión de aquel pensamiento particular sobre el objeto. Nuestras 'actitudes epistémicas' - para usar la frase de Evans- en dirección a los pensamientos que abrigamos, juegan efectivamente un rol en la determinación del sentido. Por eso, ¿qué rol -si es que hay alguno- atribuiríamos a esta tesis de prioridad en la identificación de la filosofía analítica?

MD: Ciertamente no puede hacerlo por doctrina, como usted ha dicho. Se podría tomar la actitud de que, una vez que la tesis de prioridad es rechazada, se está dentro de la filosofía post-analítica o algo así. Podría tomarse eso como una característica definitoria. Pero pienso que estaría equivocado, o en todo caso de escasa ayuda. Pienso que la gran diferencia entre los filósofos analíticos y otros es probablemente que todo filósofo analítico asume algo que tiene cierta remembranza con el tipo de semánticas en las que subyace la lógica matemática, es decir, la semántica fregeana. No necesariamente en todos los detalles, pero ellos asumen siempre algo de esa estructura, donde los componentes de los enunciados o los componentes de los pensamientos -uno proyecta y moldea la estructura de los pensamientos sobre la estructura de los enunciados- contribuyen a los valores semánticos de enunciados completos o pensamientos completos. Esa contribución es algo que va en dirección a fijar la verdad o la asertabilidad.

FP: Entonces, ¿es la composicionalidad la característica definitoria?

MD: No justamente la composicionalidad como un principio general, sino composicionalidad en relación con alguna idea de una sintaxis aproximadamente similar a la lógica de predicados estándar. Eso es muy vago y podría ser difícil de aplicarla a algunos de los filósofos del lenguaje ordinario. Pero, pienso que es sin embargo su base y que distingue a los filósofos analíticos de otros.

\footnotetext{
${ }^{20}$ Evans, G., Collected Papers, pp.291-321. La cita es de p. 301. Ver también hacia el final de la sección IV, pp. 308-311 las consideraciones sobre 'estados epistémicos', 'keeping track' de un objeto y 'having hold' de un objeto.
} 
Muchos prestan poca atención a la lógica matemática. No obstante, es parte de la formación de todos ellos. Es lo que subyace en la perspectiva que tienen sobre el significado y el contenido.

FP: Entonces ¿es una cuestión de estilo? Mucha gente en la filosofía analítica hoy en día no está interesada ni directamente ni indirectamente por la lógica matemática.

MD: La lógica matemática es una vasta estructura que va mucho más allá de la parte elemental, la cual puede ser todo lo que ellos hayan aprendido. Pero la lógica elemental está, no obstante, en la base de su concepción del lenguaje y el pensamiento, mientras que puede no ser así para aquellos que carecen de aquel conocimiento elemental. Actualmente no sé como es. Si usted estudia filosofía en una universidad francesa, ¿se le enseña lógica matemática elemental?

FP: Sí, se enseña, a pesar de que la mayoría piense que es enteramente irrelevante para profundizar cuestiones filosóficas. La ven como una cuestión puramente técnica.

\section{Anti-realismo, verificacionismo y la filosofía de la mente}

FP: Tengo una serie de preguntas para formularle acerca de la relación entre la filosofía del lenguaje, la filosofía de la mente y el anti-realismo. Permítaseme comenzar con un tipo de anti-realismo que usted ha defendido, o mejor con la clase de desafío que usted piensa que el realismo debe encontrar. Mucha gente tiene la sensación de que en el tipo de semántica a la que usted adhiere debe estar asociada a alguna forma u otra de verificacionismo. Están por ejemplo las críticas de Michael Devitt ${ }^{21}$, que descansa ciertamente sobre una interpretación de este tipo, y también la de Stephen Schiffer, quien, en Remarks of Meaning está muy cerca de acusarlo de ambas cosas, de verificacionista y de conductista ${ }^{22}$. Por supuesto, estas son posiciones filosóficas a las que supongo que nadie adhiere hoy en día. Aún así, es tentador pensar que una teoría anti-realista del significado es cercana, sino idéntica a una teoría verificacionista del significado. ¿Cuál es la diferencia principal entre el anti-realismo como usted lo concibe y esta posición de algún modo anacrónica? ¿Cómo trazaría la distinción entre las dos?

MD: Usted dijo que ya nadie sería un verificacionista. He usado realmente en el pasado el término "verificación", pero no considero que haya sido

${ }_{21}$ Michael Devitt's, Realism and Truth. Princeton University Press, Princeton, 1984, ch.12.

${ }^{22}$ Schiffer, S., Remarks on Meaning. The MIT Press, Cambridge, Mass., 1987, sec.8.4. 
una expresión muy feliz. "Justificación" es mejor, y la idea que defendí es que el significado de un enunciado está dado por el tipo de justificación que se le pueda dar.

Hay un gran contraste entre el verificacionismo del Círculo de Viena y el tipo de teoría del significado que yo defiendo, la cual se apoya en el rechazo para mí es eso- de ese tipo de atomismo que estaba implícito en la idea de los positivistas. Los positivistas hablaban como si cada oración pudiese ser considerada como poseyendo un significado independientemente de su pertenencia a un lenguaje; esto es, independientemente de que hay otras oraciones relacionadas con ella. La verificación consistiría, en el fondo, en alguna secuencia de experiencias sensitivas. Ahora, eso obviamente carece de sentido. No se puede tener una teoría del significado que ignore el hecho de que nuestras oraciones son parte del lenguaje y mantienen relaciones con otras oraciones. En general, la justificación de cualquier aserción, de cualquier enunciado, será algo que incluya no solamente una experiencia, sino también inferencias. Este es exactamente el contraste que se realiza en el famoso artículo de Quine, "Two Dogmas of Empiricism" ${ }^{23}$. Él rompe con la imagen del lenguaje como una estructura articulada con algunas cosas...

FP: ...en la periferia...

MD: ...y en algunas cosas más adentro, también. Piense en la concepción del significado que él emplea - y no estoy diciendo que yo esté totalmente de acuerdo con ella, tal como está postulada. El hecho es que él no ataca el positivismo por ser verificacionista como tal. Por el contrario, la imagen que lapida, está enteramente relacionada con la conformidad con la experiencia de la estructura de las oraciones, y de los valores de verdad asignados a aquellas oraciones. La experiencia tiene un impacto sobre la estructura como un todo. Por eso, todavía esto es entendido en términos de verificación (o falsación, si le gusta) y en términos de los ajustes que deben ser hechos en la estructura bajo el impacto de la experiencia. Lo que él ataca es la concepción de acuerdo con la cual cada oración, por decirlo así, se erige por sí sola y espera ver si algo tiene un impacto sobre ella.

FP: Como si estuviese aislada del resto del lenguaje.

\footnotetext{
${ }^{23}$ El artículo fue reimpreso en Quine From a Logical Point of View. Nine Logico-Philosophical Essays, Harvard University Press. Cambridge, Mass., 1953, pp.20-46.
} 
MD: Exactamente. Es claro que el impacto puede ser transmitido desde la periferia hacia el centro y que la transmisión se hace por conexiones inferenciales, a pesar de que él no describa exactamente cómo. Pero el punto es éste: a lo largo del modelo empirista, no se podría pensar en la justificación, simplemente, como alguna secuencia de experiencias sensibles. Puede tomar cualquier forma que le guste. Eso es porque los positivistas tuvieron que hacer la dicotomía entre enunciados empíricos y enunciados matemáticos.

FP: O enunciados "formales" en general...

MD: ...aquellos tienen un tipo completamente diferente de significado. Pero en la concepción que estoy sosteniendo, existe un rango. Existen sólo enunciados observacionales puros -si puede afirmarse que exista alguno- que pueden ser verificados directamente, sin ninguna mediación de la inferencia. En el otro extremo, hay cosas que están establecidas puramente mediante el razonamiento, como los teoremas matemáticos, y la mayoría de las cosas ocupan alguna posición intermedia. Así, ese es el contraste entre verificacionismo y anti-realismo.

De alguna manera la diferencia depende de lo que se entienda por 'verificación'. Si 'verificación' significa que se realiza en términos de cómo nosotros determinamos un enunciado como verdadero o falso, entonces mi teoría del significado es verificacionista. Excepto en que yo no quiero insistir en que para todo enunciado, hay una manera de establecerlo conclusivamente. Estoy perfectamente preparado para admitir que existen algunos enunciados para los cuales no existe un modo concluyente de determinación. Hay siempre casos en los que los enunciados pueden ser derribados posteriormente, en los que son susceptibles de revisión. Es una característica del significado de ciertos enunciados que pueden ser confirmados, pero no conclusivamente determinados. Podría llamarse a esto verificacionismo en sentido general, si usted quiere, pero no en el sentido atomístico, y no prejuzgando qué forma podría tomar la justificación.

Pienso que 'justificación' es probablemente un término mejor. Originalmente usé 'verificacionismo' porque quería impactar un tanto a la gente. Todos decían: "el positivismo ha sido ahora refutado". Nunca tuvieron una buena explicación de por qué había sido refutado. En mi opinión, Quine fue la persona que lo refutó. La mayoría sólo sabía que no creíamos más en aquello, pero no tenían ningún argumento. De esta forma llegaron a ser impactados. Yo quería afirmar que no era el componente verificacionista sino el componente atomístico lo que estaba equivocado.

FP: ¿Desea aún sostener la distinción analítico/sintético? 
MD: Sí. Creo que está equivocado el querer tirarla por la borda.

FP: Entonces, en resumidas cuentas, usted piensa que el significado de las oraciones está determinado o fijado por, digamos, sus condiciones de justificación, pero que esas condiciones no pueden ser construidas de un modo atomístico.

MD: Es exactamente correcto. Ante todo, creo que estas condiciones incluyen usualmente un componente de inferencia. Por decirlo de algún modo: el lenguaje es dependiente del lenguaje.

FP: Pero, si las condiciones de justificación no pueden ser construidas atomísticamente, ¿deberían ser, pues, construidas holísticamente? La comprensión de una oración dependerá siempre de la comprensión de las oraciones que están presentes de algún modo en uno de los trayectos desde ella hacia la periferia o desde la periferia hacia ella ¿No está marcando eso una dirección hacia el holismo?

MD: No lo creo. Se llega al holismo si es abolida la distinción entre periferia e interior ¿cierto?

FP: Entonces, ¿quiere usted separar la distinción periferia/interior de la distinción analítico/sintético?

MD: Quiero tener una dirección. Obviamente la inferencia trabaja en ambas direcciones. Quiero tener una relación de dependencia del significado que vaya, digamos sucintamente, únicamente en una dirección porque pienso que no podríamos dominar el lenguaje si el holismo fuese correcto. Pienso que ciertamente no podríamos dar una descripción sistemática de cómo el lenguaje funciona si el holismo fuese correcto.

¿Podría agregar algo? Gran parte del ataque a la distinción analíticosintético tiene que ver con un rasgo observado de los lenguajes naturales, digamos, que hay mucho de juego. Eso está ciertamente justificado. Si se quisiera dar una teoría sistemática del significado, se tendría que parcelar el sentido, por así decir, entre diferentes palabras y construcciones del lenguaje y, probablemente, no hay un único modo de hacer eso. Si se nos pidiese que explicásemos el significado, o que explicásemos lo que alguien debe conocer en orden a conocer el significado de diferentes expresiones, probablemente le asignaríamos el mismo significado a diferentes expresiones. Eso genera algún tipo de holismo en una comprensión del lenguaje. No tenemos un modo preciso de decir: 'Bien, si no 
entendemos eso, entonces esa es la palabra cuyo significado no conocemos'. Por otro lado, esto contrasta con el tipo de esquema rígido fregeano donde cada expresión tiene su sentido perfectamente determinado. Creo que es un ideal en orden al cual conscientemente nos esforzamos cuando lo necesitamos, y lo necesitamos cuando se producen disputas o incertidumbres sobre lo que son nuestras justificaciones. Construimos teorías, y cuando hacemos esto, tenemos que llegar a algún acuerdo de lo que será tenido en cuenta como sentido, o la definición de éste o aquel término, de modo que ordenamos las cosas y las hacemos aproximar al esquema fregeano.

Con esto no quiero decir que la distinción analítico/sintético tenga una aplicación absolutamente determinada a nuestro lenguaje tal como es. Pero no quiero pensar que es algo que debe ser eliminado. Por el contrario, es algo que necesitamos usar cuando estamos tratando de resolver desacuerdos o comprender justificaciones de lo que sólo creemos de un modo vago.

FP: Me gustaría volver a la oposición entre la filosofía del lenguaje y la filosofía de la mente. Hablábamos de ella con relación a la tesis de la prioridad y su rol en la identificación de la filosofía analítica. Pero, me gustaría que hablásemos sobre la posibilidad de una filosofía anti-realista de la mente en conexión con la tesis de la prioridad.

Usted ha dicho que las raíces de la noción de verdad (o falsedad) de un ítem lingüístico (una oración, un enunciado) recae en la distinción entre un hablante que está objetivamente en lo correcto, u objetivamente equivocado en lo que dice cuando realiza una aserción ${ }^{24}$.

Si ese es el caso, entonces, la noción de aserción, de un modo u otro, es más fundamental que la noción de verdad. Ahora, es difícil de ver cómo podríamos dar un análisis satisfactorio de la noción de aserción sin tener en cuenta nociones psicológicas: nociones tales como creencia, deseo, intención, y otras semejantes ${ }^{25}$. Entonces, si la noción de aserción es más fundamental que la de verdad, y si necesitamos la noción de aserción para dar cuenta filosóficamente de la noción de verdad, parece que tenemos que recurrir a nociones psicológicas para explicar la noción de verdad. ¿Deberíamos?

MD: Comprendo la pregunta. Me gustaría decir primeramente algo que no es directamente una respuesta a la pregunta, sólo para clarificar la posición

\footnotetext{
${ }^{2+}$ Truth and Other Enigmas, p. xvii.

${ }^{25}$ Ver, por ejemplo, una vez más Truth and Other Enigmas, p. xvii.
} 
que deseo defender. Creo que la noción de aserción correcta e incorrecta es mucho más primitiva que la noción de verdad. Hay muchos ejemplos en la filosofía de gente que afirma: 'Tal y tal formas de proferencias no son enunciados que definen condiciones de verdad'. Mucha gente afirma esto sobre los condicionales, por ejemplo, Hilbert lo dijo sobre los enunciados matemáticos con cuantificadores no-ligados. Ahora, lo que estaban diciendo es que se tiene que interpretar esos enunciados haciendo una suposición. Es muy claro en las instancias más simples, por ejemplo en la interpretación de Hilbert de los enunciados con cuatificadores existenciales como comunicaciones incompletas. La idea es que tenemos una justificación de ellos si podemos producir una instancia. Dentro de esta perspectiva, la distinción crucial no se da entre verdad objetiva y falsedad objetiva. La distinción crucial se establece en términos de lo que nosotros podemos hacer, en términos de si nosotros podemos o no justificar nuestra afirmación. Y eso se ajusta bien con la idea de una aserción correcta vs. una aserción incorrecta.

La diferencia entre esta perspectiva y considerar una aserción como si poseyese un valor de verdad objetivo es que las condiciones de verdad tienen que ser independientes de mi condición epistemológica, de cualquier cosa que yo pueda hacer, a menos que, por supuesto, el enunciado sea sobre mí mismo. La idea es pues, que la aserción es determinable como verdadera o como falsa, independientemente de que yo pueda justificarla o no. Mientras que en la otra perspectiva pensamos justamente en términos de si yo puedo justificar la afirmación que hago. Eso es lo que quiero decir cuando digo que la noción de aserción traza una ruta, por así decirlo, conduciendo hacia la noción de verdad. Pero se debe avanzar más si se quiere alcanzar la noción de verdad propiamente dicha. Es sólo el comienzo en esta dirección. Para alcanzar la noción de verdad, uno debe preguntarse: ¿Por qué no puedo simplemente tomar esto como si realizara una afirmación? ¿Por qué tengo que darle algún sustento objetivo, independientemente de mí?

Pienso que el punto de su argumento que yo rechazaría es la suposición de que la aserción tiene que explicarse psicológicamente. Conozco que hubo una fase en la que ambos, Russell y Wittgenstein habrían sostenido eso, pero yo no lo creo. Pienso que es un asunto complicado. Tenemos una aserción como un acto externo. Está usted ahí con una oración que tiene que entender, digamos, asertóricamente, y está también el acto interno de juzgar, cuando se juzga algo como verdadero. Creo que es mejor considerar el juicio como una internalización de los actos externos de aserción, más que a través del otro rodeo, es decir, que considerar la aserción como una expresión de un estado interno o un acto interno. 
Hay una pregunta que aparece en algún lado de Investigaciones Filosóficas: '¿Qué es el lenguaje como juego de aserción?'. Realmente, Wittgenstein piensa que no hay tal cosa como una aserción. Existen estos varios y diferentes casos. Pero creo que es sin embargo, una pregunta perfectamente correcta de formular.

Estamos poco tentados a explicar qué es dar una orden en términos psicológicos. Normalmente hablando, si una persona está en una posición de autoridad con respecto a otra cuando emitimos una orden, uno normalmente asume que esa persona quiere que la otra haga lo que le mandó hacer. Pero no se tiene que asumir que esa persona podría tener otros motivos para darle a la otra una orden. El hecho es que si aquella realmente está en una posición de autoridad, le está justamente dando una orden y esto tiene ciertamente efectos, sea cual fuese la razón por la que aquella diese la orden. Lo que tenemos que hacer es describir el juego de lenguaje de la orden, y yo pienso que lo mismo se da para la aserción. No es tan obvio en este caso, porque las consecuencias no son evidentemente claras al modo en que las consecuencias de dar una orden lo son. Eso lo hace mucho más complicado de describir, pero pienso que así es como debe ser descrito el lenguaje, como un juego de comunicación, que consiste en que la gente dice cosas, más que algo sobre los estados internos. Por eso no creo que debamos acudir a la intención o a la creencia; o si usted tiene que acudir a la intención, es sólo en un estadio muy sobre el final, si lo hubiese.

FP: Entonces, ¿lo que usted requiere es meramente de una descripción del acto lingüístico de la aserción? ¿Y puede usted darla sin tomar en cuenta intenciones, creencias, deseos, y otras actitudes proposicionales?

MD: Eso es lo que espero. Quiero decir, si usted dice: Correcto. ¡Ve y hazlo!- No puedo. Porque esto descansa en una teoría general del significado y no sé exactamente cómo hacer eso.

FP: No se lo voy a pedir entonces. A cambio, voy a formularle algo más. Mi segunda pregunta sobre la filosofía del lenguaje vs. la filosofía de la mente concierne directamente al contenido del debate realismo vs. anti-realismo. Este debate, tal como usted lo concibe, no puede darse meramente en términos lingüísticos (oraciones, enunciados) debido, al menos, a tres razones. Para comenzar, sería también sobre creencias y estados de creencias porque también evaluamos creencias y estados de creencias en términos de verdad y falsedad. En segundo lugar, significado es una noción cognitiva. Es lo que los hablantes y agentes competentes comprenden o conocen, cuando comprenden el significado de las oraciones o conocen cuál es ese significado, y la cuestión de conocer cómo 
el significado se representa mentalmente concierne plenamente al debate. Finalmente, el problema de decidir si la cuestión de la verdad debe estar epistemológicamente constreñida o no, concierne directamente a la naturaleza del concepto de verdad que podemos o no formar legítimamente.

Dado que el debate no puede ser meramente sobre la comprensión lingüística, y debe ser también sobre la formación de los conceptos, ¿no sería posible, por no decir obligatorio, interpretarlo como un debate legítimo en la filosofía de la mente, no únicamente sobre el significado de oraciones, sino sobre contenidos mentales?

MD: Bien, puedo acordar con usted. Ciertamente, no pensaría que este es un tópico que tiene una enorme relación a estas disputas metafísicas sobre el realismo - como lo hago- si creyese que es simplemente una cuestión de lenguaje, tan solo un poquito de semántica. Estábamos hablando antes sobre la tesis de la prioridad. Ahora, si uno es un seguidor de Evans o Peacocke y piensa que tiene que describir la estructura de nuestros pensamientos independientemente de sus expresiones lingüísticas, la misma dicotomía aparece, sin embargo, entre dar cuenta en términos de condiciones de verdad -lo que tiene que ser el caso para que un pensamiento sea verdadero- y dar cuenta en términos de, digamos, justificación, sobre la base de si puede reconocerse como verdadero. Por eso la misma cuestión aparece allí, como manifiestamente en Evans y Peacocke.

FP: ¿Concluiríamos que no hay ventajas en ver esto como un debate en la filosofía de la mente?

MD: No pienso que haya ninguna ventaja. Como usted sabe yo creo en la tesis de la prioridad. La diferencia entre estos dos enfoques es que el enfoque de la filosofía de la mente o de la filosofía del pensamiento tienden a ser solipsistas. Se habla sobre los sujetos individuales, sobre lo que el contenido de un sujeto individual puede ofrecer al pensamiento, como él reconoce que el pensamiento es verdadero, etc. Y no tiene mucho que ver -al menos normalmente- con la comunicación, mientras que yo pienso que usted probablemente no obtendrá una buena respuesta si no discute en términos de comunicación. Pero esta es una cuestión muy extensa.

FP: Hay dos cuestiones diferentes respecto de la tesis de la prioridad. Hay una cuestión metodológica, y una cuestión sobre el contenido del realismo vs. anti-realismo. Un problema es decidir si la filosofía del pensamiento puede o no ser enfocada únicamente a través de la filosofía del lenguaje, o si el lenguaje es prioritario o no al pensamiento en orden a la explicación. Esa es una cuestión 
metodológica y es una cosa. Otra cuestión es decidir si el debate es o no también sobre el contenido mental. Claramente lo es, en cuanto lo que se está debatiendo es si el significado de una oración está determinado por sus condiciones de verdad; entonces, el problema de saber si el contenido del pensamiento expresado en la oración está o no determinado por sus condiciones de verdad, es también parte del debate.

Así, hay por cierto dos cuestiones distintas: la cuestión metodológica y la cuestión del contenido. Me parece que la posición que usted elige como prioritaria no tiene que darse en menosprecio de la segunda. Son lógicamente diferentes. Por eso, el vuelco respecto al axioma fundamental de la filosofía analítica no hace una diferencia y está perfectamente legitimado comenzar con la cuestión del contenido de nuestros pensamientos. Por otro lado, tenemos aquí los mismos problemas.

MD: Creo que es perfectamente verdadero. Considero que es una cuestión de metodología. Usted tiene efectivamente los mismos problemas. Y eso es porque en gran medida, como usted dice, el vuelco no impide realmente la comunicación entre la gente que está de un lado o del otro. Pero, hay un punto en el cual divergen y que tiene que ver con la metodología. Esto es: el filósofo del pensamiento no se informa mucho sobre lo que tenga que ver con el intercambio verbal, mientras que obviamente, el lenguaje es prioritario en el orden de la explicación. El lenguaje es una cosa comunal. En primer lugar un modo de comunicación.

FP: ¿Es precisamente porque es una cuestión comunal que usted quiere sostener la tesis de la prioridad?

\section{MD: Sí}

FP: Ahora bien, los pensamientos fregeanos son una cosa comunal. Alguien puede argüir muy bien a favor de la tesis de la prioridad sobre la base de que tiene la ventaja de evitar el psicologismo. Pero, i cual es el escollo del psicologismo sino creer que los pensamientos son parte de una corriente de conciencia? Me parece que una cuestión crucial es, entonces, decidir si la confusión entre Gedanke y Vorstellung no se sigue necesariamente del rechazo de la tesis de la prioridad. Supongamos que seguimos la sugerencia de Evans que discutimos antes. ¿Estamos de este modo haciendo psicología en el sentido criticado por Frege y Husserl? ¿Tenemos que argüir que el modo en el cual se piensa el referente, su modo de representación al nivel de los pensamientos es parte de una corriente de conciencia? Si sólo por las razones fregeanas uno podría decir: 'Sí, 
hay un punto para sostener la tesis de la prioridad. Esta ofrece una buena protección en contra de escollos del psicologismo'. Pero, ahora, ¿es la confusión entre Gedanke y Vorstellung realmente inevitable? ¿No hay modos de evitar la confusión cuando se rechaza la tesis de la prioridad?

MD: Por supuesto, esto dista de ser tan rápido como decir: 'En el momento en que usted hace esto, cae en el psicologismo'. No estoy diciendo esto. Pero pienso que es necesario para el filósofo del pensamiento, tanto como lo es para el filósofo del lenguaje, respetar el principio del contexto. Si consideramos lo que Evans afirmó sobre los modos particulares de pensar sobre un referente y lo que dijo sobre los referentes singulares, pensamientos singulares, etc. tenemos que reconocer que el modo en que pensamos sobre un objeto particular es parte de un pensamiento completo. El modo en que pensamos de un objeto constituye un ingrediente de un pensamiento completo. No tiene ningún sentido hablar acerca de él independientemente de ...

FP: ... del contexto en el cual está enmarcado.

MD: Esto es correcto independientemente del contexto en el cual se piense que algo es el caso con el objeto en cuestión. Se debe hacer la pregunta: '¿Qué es tener un pensamiento completo? ' A menos que se quiera caer en las explicaciones psicologistas de esto, debe tratárselo, como Frege mismo lo hizo, como un objeto de una actitud proposicional. Es creer algo, o creer que algo es el caso. Tiene que ser el contenido de una actitud proposicional. Eso es exactamente lo que hace Peacocke. Él construye la cosa completa, haciendo primero posible caracterizar las actitudes que un ser humano que quizá no hay adquirido una lengua, pueda sin embargo manifestar ${ }^{26}$. danken.

FP: Y él toma los pensamientos como los pensamientos fregeanos, $\mathrm{Ge}$ -

MD: Son exactamente como ellos, y son los objetos de creencias y deseos, o una de estas cosas. Aún no creo que tal programa funcione pero, ciertamente, no puedo acusarlo directamente de psicologismo. Si uno pudiese dar una caracterización de estas actitudes proposicionales sin referencia a sus expresiones, la cosa podría funcionar. No creo que Peacocke o nadie más haya realmente mostrado eso.

\footnotetext{
${ }^{26}$ Ver por ejemplo, Peacocke, C., Thoughts: An Essay on Content, Basil Blackwell. Oxford. 1986.
} 
FP: Usted es bastante pesimista sobre las perspectivas de la filosofía de la mente. ¿Qué hay sobre la ciencia cognitiva?

MD: Soy pesimista sobre la ciencia cognitiva. No soy pesimista sobre esta gente -John Campbell es uno de ellos- que van en la dirección de la filosofía del pensamiento. Para comenzar, estoy seguro de que ellos descubrirán mucho en sus investigaciones aún si todas sus premisas básicas son incorrectas, aún si están equivocados al trastocar la tesis de la prioridad. Lo que descubran permanecerá y será capaz de ser transpuesto desde el pensamiento al lenguaje, en caso de que reviertan la tesis de la prioridad. En segundo lugar, pienso que es muy interesante ver qué tan lejos puede llegar eso. Una razón por la cual es interesante, es que si la cosa resulta completamente exitosa, entonces la tesis de la prioridad sería completamente incorrecta y no tendría ningún interés. Pero, aún si no fuese incorrecta, sería muy interesante ver hacia donde específicamente va un programa que se construye sobre el rechazo de la tesis.

FP: Y cuán lejos puede llegar.

MD:- Cuán lejos puede llegar exactamente. Esa es una cuestión bastante oscura. Aún Frege pensó que la tesis de la prioridad era únicamente respecto de nosotros. Él pensó que los seres humanos sin lenguaje podrían captar los mismos pensamientos tal como nosotros lo hacemos, sólo que no vestidos en la expresión lingüística. Pero él no dio ninguna explicación de cómo sería eso. ¿Qué significa esto? Si la gente que avanza por la filosofía de la mente está acertada, estará brindando una explicación a ello. Es sólo una cuestión de hecho contingente -si esto puede considerarse un hecho- que nosotros podemos captar pensamientos por medio del lenguaje. ¿Qué hay acerca de nosotros que hacemos esto? Todas estas preguntas son genuinas y muy interesantes. Espero que efectivamente ellos descubran algo.

FP- Existe una tendencia muy fuerte en la filosofía analítica de desviar hacia la filosofía de la mente las desventajas, por así decirlo, de la filosofía del lenguaje. Es muy claro que la gente en los Estados Unidos se está moviendo en esta dirección. Hay más y más filosofía de la mente.

MD: En mi opinión, es de calidad pobre.

FP: La brecha entre la filosofía inglesa y la americana parece ir haciéndose cada vez más y más grande. Debido, en gran parte, al inmenso impacto de la ciencia cognitiva en los Estados Unidos. 
MD: Creo que es verdad. Y no me preocupa en lo más mínimo, porque realmente creo que la filosofía americana está en su mayor parte en un mal camino

FP: ¿Se refiere usted especialmente a la filosofía de la mente?

MD: Por supuesto esto difícilmente sea verdadero de Kripke y Putnam, y dificilmente verdadero de Davidson. Pero la tendencia general va en esa dirección científica, lo que me parece ser estéril.

FP: Se refiere usted al materialismo, fisicalismo, etc.?

MD: A todo ese asunto. No va a conducir a ninguna parte.

FP: Conduce al menos a una cosa. La posición en la que estamos ahora es exactamente opuesta a la posición en la que estaban Brentano y Husserl. Ellos consideraron la intencionalidad como la marca irreductible de lo mental, mientras que nosotros nos consideramos a nosotros mismos simplemente como carne y sangre, humanos de existencia física, y nos preguntamos: ¿'Cómo puede éso tener intencionalidad? ¿Cómo podrían las máquinas, o lo que podría ser descrito en términos puramente físicos, tener intencionalidad y pensamientos? $Y$ tratamos de dar cuenta de la intencionalidad en términos naturalísticos.

MD: Muy bien, esa es una pregunta filosófica que hay que formular. Pero espero realmente que la filosofía inglesa mire mucho más en la dirección de lo que está pasando en otros países europeos y mucho menos en lo que está sucediendo en América. Es la lengua lo que lleva a muchos a hacer eso. Es mucho más fácil leer artículos en las revistas americanas. Es entretenido. Está toda esa gente como Jonathan Barnes, Kevin Mulligan, Peter Simmons, etc. que se entrenan ellos mismos para enseñar en el extranjero. Muy pocos graduados hacen esto. La mayoría, creo, a causa de la lengua. Eso nos retrotrae al inglés que se enseña en las escuelas. Deberíamos, tal vez, tener cursos de lengua para estudiantes graduados, requerirle, al menos que manejen una lengua europea.

FP: Para volver a la situación con respecto a los EE.UU. Es muy impresionante que, por ejemplo, su trabajo no tenga mucho eco allí. Muy pocas personas realmente se ocupan de leerlo. Putnam es uno. Brian Loar y Paul Horwich, que enseñan en América también lo leen cuidadosamente. Fue la misma situación con Gareth Evans. Pocos filósofos americanos se han molestado en leerlo. 
MD: Eso es verdad, y fue una gran lástima. Creo que Putnam fue parcialmente responsable de eso. Escribió una reseña horrible sobre The varieties of reference y lo defenestró completamente. No sé por qué lo hizo. Hizo un juicio muy descalificador. Puede no haber tenido mucha influencia. Puede haber sido un síntoma, más que una causa. No sé. Pero es ciertamente verdadero que ellos tendrían que leer a Evans y es un error muy serio que no lo hagan. Hay mucha riqueza en ese libro.

\section{Anti-realismo y ética}

FP: Tengo una última pregunta. Es sobre ética. Puede ser que no exista tal cosa como una doctrina filosóficamente consistente, una mirada o una $\mathrm{Wel}$ tanschaung que podamos llamar anti-realismo global, y que consistiría en un anti-realismo sobre la matemática $y$ el mundo natural $y$ la vida mental de otros $y$ los agentes morales, etc.

MD: Puede ser.

FP: Pero el hecho es que usted nunca ha sostenido este tipo de posición. Existe, sin embargo, un rango de disputas filosóficas que comparten la forma común, como usted dice, de un conflicto entre una visión realista y una antirealista o la interpretación de los enunciados de una clase dada, es decir, enunciados matemáticos, enunciados sobre el mundo natural, la vida mental de otros, los mandatos éticos, etc. El debate, tal como usted lo concibe y tal como otras personas como Crispin Wright lo ha concebido después de usted, ciertamente se aplica también a la ética. Está, digamos, la cuestión del realismo sobre los hechos morales o los valores morales. Mi pregunta es: ¿Qué significa la disputa realismo- anti-realismo en la ética?

Permítaseme hacer esto más preciso. Hay al menos dos modos de expresar el realismo moral: en términos de hechos y en términos de valores. En términos de hechos, podría expresarse del modo siguiente: hay hechos morales objetivos, que son parte de la fábrica del mundo, y está el propósito de la deliberación moral que descubrimos. Existe, digamos, el hecho objetivo de que la esclavitud es injusta. Ahora, podríamos también expresar el realismo moral en términos de valores. El realismo moral podría expresarse como sigue: algunas acciones, prácticas e instituciones deben ser adoptadas o, por el contrario, criticadas y abandonadas, según ellas fomenten o promuevan valores que son objetivamente justificados en su aceptación, o por el contrario en su rechazo. El propósito de la deliberación moral es descubrir qué valores debemos adoptar y cuáles debemos rechazar, y cuando descubrimos eso, descubrimos algo objetivo. Para 
volver al ejemplo de la esclavitud, un realista expresaría su posición argumentando que los valores asociados con la institucionalización y la práctica de la esclavitud tienen que ser abolidos y que las razones que tenemos para hacer eso son razones objetivas. El propósito de las deliberaciones morales es hacer posible la toma de decisiones en todos los casos en los cuáles pueden ser menos claro que la esclavitud, digamos, por ejemplo, la eutanasia o el aborto.

Me parece que los argumentos anti-realistas en contra del realismo moral construido en términos de hechos serían un argumento que sustenta una forma u otra de no-cognitivismo. Si estoy en lo cierto, un anti-realista argumentaría que las afirmaciones morales son cognitivamente vacías en el sentido de que no podemos informar acerca de hechos morales. Simplemente no hay ninguno que descubrir. La pregunta que quiero hacerle es la siguiente: ¿Qué sostendría un anti-realista en contra de un argumento de un realista moral, constituido en términos de valores? ¿Debe un anti-realista mantener alguna forma $u$ otra de relativismo y argumentar que nuestras acciones, prácticas, instituciones, etc. son o bien justas o bien injustas únicamente relativamente a un conjunto de creencias culturalmente fijadas, que forman, por decirlo así, las condiciones de base de nuestras justificaciones, por lo que todas nuestras 'justificaciones' éticas no puedan dejar de ser prejuzgadas en algún sentido muy fuerte e ineliminable?

¿Desea argumentar en favor de alguna forma u otra de anti-realismo en ética? Si es así, ¿Cuál es esa posición y como intenta argumentar a su favor?

MD: Voy a hacer un esfuerzo para contestar su pregunta. Solamente podría darle una respuesta muy programática porque, aunque me avergüence, nunca he dedicado tiempo a pensar esto. No porque haya creído que podemos muy bien estarnos sin ello. Simplemente no he pensado mucho sobre eso.

Me parece al menos, que la aplicación de estas ideas anti-realistas a la ética deberían cambiar los términos del debate, por las siguientes razones. El tipo de anti-realismo al que yo adhiero no es un subjetivismo de ninguna clase. Es completamente objetivo, o asume objetividad, en el sentido de que si un enunciado se justifica o no es una cuestión objetiva. Sólo piense en el caso de la matemática. Si usted tiene o no una prueba de un enunciado, es una cuestión objetiva. No estamos hablando en términos de si un enunciado es verdadero respecto a alguna realidad moral independiente. Estamos hablando acerca de hacer una afirmación cuya justificación suena objetivamente o no suena objetivamente. Si uno adopta esta posición anti-realista, en este caso en la dirección de la ética, no habría ningún lugar para una posición subjetivista. Creo que calificarla como nocognitivista sería también equivocado. La justificación es un asunto de justifica- 
ción cognitivista. Por otro lado, uno no pensaría que la única alternativa de una visión subjetivista de la ética sería un tipo de imagen realista de los enunciados éticos, como si éstos describieran una realidad que existe independientemente de nosotros, o que realizaran afirmaciones que son objetivamente verdaderas o falsas. La explicación de esos enunciados deben dar cuenta del hecho de que una persona que los hace es, en principio, capaz de justificarlos. Uno tendría que investigar esto y no puedo decir mucho sobre qué tipo de justificación exactamente necesitaríamos tener, qué tipo de enunciado ético sería constitutivo de una justificación ética.

FP: Qué tipo de enunciado normativo en particular.

MD: Correcto. No lo voy a intentar ahora. Pero esa sería la línea que se tendría que tomar si se quisiera ver como sería el anti-realismo ético. Pienso que sería probablemente una posición intermedia.

FP: Puede ser algo semejante a la posición de Wiggins. Wiggins quiere defender el cognitivismo acoplándole una idea de subdeterminación con respecto a las afirmaciones morales ${ }^{27}$. Desde esta perspectiva, el cognitivismo es un aliado natural del realismo. También tendemos a pensar que el teísmo es un aliado natural del realismo. Usted habla del teísmo muy al final de The logical Basis of Metaphysics ${ }^{28}$.

MD: No mucho.

FP: Puede ser, pero usted sugiere, no es cierto, que el teísmo no es necesariamente un aliado del realismo.

MD: Eso es lo que quisiera sostener. Esta podría ser una transición inteligente, pero permítaseme volver a Platón y al viejo dilema '¿Algo es bueno porque Dios lo quiere, o Dios lo quiere porque es bueno?' A. J. Ayer fue muy agudo cuando sostuvo que la segunda parte de la pregunta resulta una sugerencia inválida y que, por lo tanto, Dios es irrelevante para los juicios éticos. Wittgenstein, por el contrario, toma partido a favor de la primera y considera la segunda como completamente superficial. Me parece a mí ahora que, por supuesto, si alguien cree que tiene razones para pensar que Dios quiere o nos manda o desea

\footnotetext{
${ }^{27}$ Véase Needs, Values, Truth, Basil Blackwell, Oxford, 1987, especialmente pp.124-32.

${ }^{28}$ El texto revisado de las Disertaciones de Harvard William James, 1976 se publica ahora como The Logical Basis of Metaphysics, Duckworth, London, 1991. Las observaciones sobre el teísmo se encuentran en el capitulo 15. pp. 348-51
} 
que actuemos de una cierta manera, esto, por sí mismo, debe ser razón suficiente para actuar de algún modo. Pero entonces, usted tiene que recurrir a algún particular medio de conocer qué es lo que Dios quiere. Mientras que la visión tradicional ha sido que nosotros podemos percibir qué es correcto y qué es incorrecto y deducir de eso lo que Dios quiere que hagamos. Permítaseme simplemente decir que la dirección de nuestro argumento debe darse ciertamente a lo largo de la segunda línea.

FP: Creo que hemos conversado ya un largo tiempo. Podríamos detenernos aquí. Muchas gracias.

MD: Gracias. He disfrutado mucho nuestra discusión.

Traducción : Adriana Gonzalo de Aguirre 